\title{
Avaliação de uma Pastagem de Coastcross-1 (Cynodon dactylon (L.) Pers) sob Diferentes Níveis de Matéria Seca Residual ${ }^{1}$
}

\section{Marcelino Bortolo 2 , Ulysses Cecato ${ }^{3}$, Elias Nunes Martins ${ }^{3}$, Clovenilson Claudio Perissato Cano ${ }^{4}$, Marcia Regina Coalho ${ }^{5}$, Marcos Weber do Canto ${ }^{3}$, Geraldo Tadeu dos Santos ${ }^{3}$}

\begin{abstract}
RESUMO - O experimento foi realizado no período de agosto de 1997 a abril de 1998, com o objetivo de avaliar uma pastagem de Coastcross -1 (Cynodon dactylon (L.) Pers), em quatro níveis de resíduo de matéria seca (RMS: 1978, 2130, 2545 e 3857 kg de MS/ha), com lotação contínua e carga animal variável. Foram determinadas a produção de matéria seca (PMS), a taxa de crescimento do pasto (TC), a acumulação líquida de MS (ALMS), a altura das plantas (AP), a porcentagem de solo descoberto (SD), a participação dos componentes botânicos na pastagem em porcentagem de material morto (MM) e de folhas verdes (FV), a relação folha/colmo (F/C) e a quantidade de folhas verdes/ha (FV/ha). Foi utilizado o delineamento inteiramente casualizado, com duas repetições. A PMS e TC não apresentaram relação significativa com os níveis de RMS e os dias de utilização da pastagem. A AP aumentou linearmente com o incremento dos níveis de RMS e decresceu de forma linear com o passar dos dias de experimento. A porcentagem de SD e MM decresceu linearmente, à medida que aumentou o RMS na pastagem, mas elevou-se no decorrer dos dias de experimento em todos os RMS. Para a relação F/C, porcentagem de FV e a produção FV/hectare, ocorreu comportamento linear semelhante, aumentando conforme o aumento dos níveis de RMS e diminuindo ao longo do período do experimento.
\end{abstract}

Palavras-chave: altura de planta, folhas verdes, matéria seca, material morto, relação folha/colmo, taxa de crescimento

\section{Evaluation of a Coastcross-1 (Cynodon dactylon (L.) Pers) Pasture on Dry Matter Levels under Grazing}

\begin{abstract}
The trial was carried out from August/1997 to April/1998, aiming to evaluate Coastcross-1 (Cynodon dactylon (L.) Pers) grazed pasture, at four levels of dry matter residue (DMR: 1978; 2130; 2545; $3857 \mathrm{~kg}$ of DM/ha) under continuous stocking grazing with variable stocking rate in relation to dry matter production (DMP), pasture growing rate (GR), net accumulation rate of DM (LADM), plants height $(\mathrm{PH})$, uncovered soil percentage (NS), participation of botanical components in percentage of dead material (DDM) and green leaves (GL), leaf/stem ratio (L/S) and quantity of green leaves/hectare (GL/ha). A complete randomized design was used with two replications. DMP and GR did not show a significant relation with DMR levels and the days of grazing. The PH increased linearly with DMR levels but decreased in the experimental period. NS and DDM decreased while DMR increased on grazing, but as grazing progressed there was an increase in all DMR levels. For LC, GL relation and GL production/ha there was a similar linear behavior, increasing while DMR levels increased and decreased in the period of the experiment.
\end{abstract}

Key Words: dead material, dry matter, green leaves, growing rate, leaf/stem ratio, plant height

\section{Introdução}

A utilização de espécies forrageiras que assegurem produtividade e qualidade ao longo dos anos e tenham crescimento vegetativo rasteiro, para a manutenção da cobertura do solo e, conseqüentemente, a garantia das características do ecossistema que envolve este processo, pode ser alternativa para elevar os índices de produtividade e produção na pecuária nacional.

A disponibilidade de forragem de qualidade e uma pressão ótima de pastejo podem permitir alto desempenho por animal e atingir o limite da produção animal por unidade de área (MOTT e LUCAS,1952). Quando bem manejada, a Coastcross-1 (Cynodon dactylon (L.) Pers) apresenta elevados teores de PB e DIVMS (HERRERA, 1983). O desconhecimento do potencial da grama Coastcross-1 na produção animal, como também do manejo mais adequado quanto à forma de utilização da pastagem, são possíveis razões do pouco uso desta gramínea entre os produtores (VILELA e ALVIM, 1996).

\footnotetext{
${ }^{1}$ Parte da dissertação de Mestrado em Zootecnia do primeiro autor - Universidade Estadual de Maringá - UEM.

2 Zootecnista - EMATER, PR, Estudante de Mestrado, UEM. E.mail: mbortolo@net21.com.br

3 Professor do Dep. de Zootecnia da Universidade Estadual de Maringá - Av. Colombo, 5790, 87020-900, Maringá - PR. E.mail: ucecato@uem.br ${ }^{4}$ Estudante de Mestrado do curso de Zootecnia da UEM.

5 Zootecnista, Bolsista Aperfeiçoamento do CNPq.
} 
Em 1967, visando melhorar a digestibilidade da matéria seca da Coastal bermuda, foi desenvolvida, nos Estados Unidos, a cultivar Coastcross-1 por meio de cruzamento com Cynodon nlenfuensis var. robustus, elevando a digestibilidade em 11 a $12 \% \mathrm{em}$ relação à cultivar Coastal (SÁ, 1996). A grama Coastcross-1 apresenta algumas características forrageiras desejáveis, como elevada produção de matéria seca (MS) por área, boa adaptação ao clima subtropical, boa relação folha/colmo e alto valor nutritivo. Em razão disto, essa forrageira é indicada para produção de feno e formação de pastagens para sistemas de produção animal.

Os resultados obtidos por VILELA e ALVIM (1996), com Coastcross-1, mostram produções de 27.448 litros de leite/ha/ano, com suplementação de $3 \mathrm{~kg}$ de concentrado/vaca/dia e taxa de lotação de 5,7 UA/ha. A produção pretendida por animal pode ser estabelecida por meio da relação consumo e quantidade/qualidade de forragem disponível com base no controle do resíduo na pastagem. DURING et al. (1980), com o objetivo de estudar o desempenho de ovinos, testaram os parâmetros resíduo na pastagem, altura residual do pasto e disponibilidade diária de forragem e observaram que o desempenho dos animais foi melhor correlacionado com o nível residual de forragem. O trabalho realizado por MOOJEN (1991) revela que a massa de forragem residual determina a produção de MS de um pasto, devido, principalmente, às alterações na sua taxa de crescimento.

O manejo das pastagens na fazenda tem como base, em alguns casos, a altura do pasto como um parâmetro prático, porque a sua relação com os níveis de resíduo é direta e a altura tem influência no consumo dos animais. WEBBY e PENGELLY (1986) constataram que a altura de azevém perene e trevo branco em pastagens constitui-se em um indicador do nível residual de forragem durante as estações do ano. Porém, este fator deve estar relacionado também com a densidade do pasto, pois para gramíneas de clima subtropical a densidade é variável em diferentes estratos.

O manejo de espécies forrageiras tem relação direta com seus aspectos morfológicos e fisiológicos, como também com a rebrota, os componentes estruturais das plantas e com a produção animal pretendida. Portanto, elevada disponibilidade de forragem de qualidade pode proporcionar ótimo desempenho por animal, mas pode limitar a produção animal por unidade de área, devido à grande parte da forragem produzida ser perdida. Como nunca se pode obter o máximo rendimento por animal e por unidade de área simultaneamente (MOTT, 1960), os fatores que interferem na produção animal devem ser estudados com critérios rigorosos de modo que satisfaçam a demanda para produto/animal e por unidade de área (MARASCHIN, 1994).

Objetivou-se com este trabalho avaliar a produção de forragem e a participação dos componentes na estrutura de um pasto de Coastcross-1(Cynodon dactylon (L.) Pers), sob diferentes níveis de resíduo de MS, utilizando-se ovelhas em pastejo contínuo, com carga animal variável.

\section{Material e Métodos}

O experimento foi conduzido no Centro de Pesquisa do Arenito/UEM, em Cidade Gaúcha, no período de outubro de 1997 a março de 1998. Esta região situase a $23^{\circ} 25^{\prime}$ de latitude Sul, $51^{\circ} 55^{\prime}$ de longitude Oeste e 554,9 m de altitude. O clima predominante, segundo CORRÊA (1996), é classificado como subtropical úmido, mesotérmico com verões quentes, geadas pouco freqüentes, com tendências de concentração de chuvas nos meses de verão.

O solo foi classificado como Podzólico vermelhoamarelo de textura média (SECRETARIA DO ESTADO DO PARANÁ,1985), que apresentou a seguinte composição química antes da calagem: $\mathrm{pH}$ em $\mathrm{CaCl}_{2}=4,9 ; \mathrm{pH} \mathrm{em} \mathrm{H} \mathrm{H}_{2} \mathrm{O}=6,1 ; \mathrm{Al}=0,00\left(\mathrm{cmol}_{\mathrm{c}} / \mathrm{dm}^{3}{ }^{1}\right)$; $\mathrm{H}+\mathrm{Al}=2,45\left({ }^{1}\right) ; \mathrm{Ca}+\mathrm{Mg}=1,34\left({ }^{1}\right) ; \mathrm{Ca}=0,89\left({ }^{1}\right) ;$ $\mathrm{K}=0,17\left({ }^{1}\right) ; \mathrm{P}=1,0 \mathrm{mg} / \mathrm{dm}^{3} ; \mathrm{C}=6,00 \mathrm{~g} / \mathrm{dm}^{3}$. Com base nos dados da análise de solos, foi feita correção do solo com calcário calcítico, em agosto de 1997, para a elevação da saturação de bases a $65 \%$.

A área experimental possuía 2,3 hectares onde estava estabelecida a pastagem de Coastcross-1 (Cynodon dactylon (L.)Pers), sendo dividida em oito piquetes (unidade experimental), com aproximadamente $2900 \mathrm{~m}^{2}$ cada, com o uso de cerca elétrica com três fios de arame $(15,45$ e $80 \mathrm{~cm}$ de altura). A disponibilização de água e sal mineral foi feita por bebedouros com bóia e cochos de madeira, distribuídos dentro dos piquetes.

A área foi adubada, em função dos resultados da análise do solo. A adubação com fósforo e potássio foi realizada a lanço e em cobertura, na forma de superfosfato simples e cloreto de potássio, respectivamente, em 15/10/97, em uma aplicação, na dosagem de $120 \mathrm{~kg} /$ ha de $\mathrm{P}_{2} \mathrm{O}_{5}$ e $100 \mathrm{~kg} /$ ha de $\mathrm{K}_{2} \mathrm{O}$. A adubação nitrogenada ( $200 \mathrm{~kg}$ de N/ha) foi fracionada 
em quatro aplicações, na forma de uréia em 10/97, 12/97, $01 / 98$ e $02 / 98$

O período experimental correspondeu a agosto de 1997 a abril de 1998. Em 12/12/97, as ovelhas foram colocadas na área para adestramento com cerca elétrica e rebaixamento do pasto por 30 dias e a partir de 06/01/98 teve início o coleta de dados referente ao experimento.

Os tratamentos inicialmente estabelecidos para as avaliações foram: $\mathrm{T}_{1}: 800 ; \mathrm{T}_{2}: 1500 ; \mathrm{T}_{3}: 2200 \mathrm{e}$ $\mathrm{T}_{4}: 2900 \mathrm{~kg}$ de matéria seca (RMS) por hectare, distribuídos inteiramente ao acaso nos piquetes, em duas repetições. No entanto, como tratamentos, utilizaram-se os resíduos reais estimados, obtidos em cada piquete, sendo: $\mathrm{T}_{1}: 1978 ; \mathrm{T}_{2}: 2130 ; \mathrm{T}_{3}: 2545 \mathrm{e}$ $\mathrm{T}_{4}: 3857 \mathrm{~kg}$ de MS/ha.

Foram utilizadas ovelhas da raça Corriedale e mestiços Bergamacia x Corriedale, sendo que o método de pastejo utilizado foi o contínuo, com lotação variável e ajustes de carga animal para manter os resíduos nos níveis desejados, conforme MOTT e LUCAS (1952). Foram utilizadas cinco ovelhas "testers", em cada unidade experimental, com idade média de três a quatro anos e peso inicial médio em torno de $38 \mathrm{~kg}$. As pesagens das ovelhas "testers" e reguladoras e os ajustes da carga animal foram feitos em intervalos de 21 dias, sem jejum prévio.

Os animais "testers" e reguladores foram everminados por ocasião da entrada nos piquetes e a cada 21 dias, em função do exame fecal parasitológico quantitativo (WHITLOCK, 1941).

As estimativas do RMS na pastagem foram feitas a intervalos de 21 dias, pelo método da dupla amostragem (WILM et al., 1944). Para isso foram coletadas cinco amostras em cada piquete, estimadas visualmente, cortadas ao nível do solo, pesadas e secadas em estufas com ar forçado a $65^{\circ} \mathrm{C}$. Utilizando-se os valores das amostras cortadas e estimadas visualmente, foi feito o cálculo do nível de matéria seca em $\mathrm{kg} / \mathrm{ha}$.

De três amostras coletadas na dupla amostragem por piquete, fez-se a separação dos componentes estruturais. Após, foram secas em estufa, sendo obtidos os valores de MS de folhas verdes, colmos verdes e material morto e sua participação percentual em cada data de coleta. O cálculo da MSFV/ha foi obtido do percentual de FV multiplicado pelo nível de resíduo na pastagem em cada data de coleta. A percentagem de folhas verdes adicionadas à porcentagem de caules verdes foi usada para estimar a MS da forragem verde.

Juntamente com a dupla amostragem foram fei- tas as estimativas de altura de plantas e a porcentagem de solo descoberto. Nesta última, avaliou-se visualmente a proporção de área descoberta da pastagem, avaliada verticalmente. A altura das plantas foi estimada utilizando-se uma régua, considerando-se a altura média das folhas mais altas.

Para a estimativa da taxa de acúmulo de MS (TC) e produção de MS (PMS), foi utilizada a equação descrita por CAMPBELL (1966), expressa em kg de MS/ha/dia, sendo a taxa de acúmulo de MS diária no período igual à diferença entre a MS de dentro e fora das gaiolas, dividido pelo número de dias nos períodos. Esta equação foi associada à técnica de triplo emparelhamento (MORAES et al., 1990), com duas gaiolas por piquete. A acumulação líquida de matéria seca (ALMS) no período foi calculada conforme preconiza HODGSON (1979), sendo ALMS igual ao resíduo de MS inicial menos o final, determinado em cada período.

A carga animal foi ajustada para manter os níveis de resíduo de matéria seca em cada tratamento, com base na taxa de acúmulo de MS estimada no período anterior, considerando-se aumento ou diminuição dos níveis de resíduo da MS, em relação ao resíduo pretendido, assim como no consumo voluntário dos animais, considerado em $3 \%$ do peso vivo em MS.

Para a análise estatística, utilizou-se o delineamento inteiramente casualizado, com quatro tratamentos (1978; 2130; 2545 e $3857 \mathrm{~kg}$ de MS/ha) e duas repetições.

$\mathrm{O}$ estudo do efeito dos tratamentos foi feito por meio de análise de regressão, adotando-se a metodologia de superfície de resposta, a partir do modelo polinomial quadrático com duas variáveis independentes, dado por:

$$
\begin{gathered}
Y_{i}=b_{0}+b_{1} R_{i}+b_{2} T_{i}+b_{3} R_{i}^{2}+b_{4} T_{i}^{2}+b_{5} \\
R_{i} T_{i}+e_{i}
\end{gathered}
$$

em que $Y_{i}$ refere às características estudadas; $\mathrm{R}_{\mathrm{i}}$, níveis de resíduo de MS/ha; $\mathrm{T}_{\mathrm{i}}$, datas de coletas (amostragens); $b_{i}$, com $i=0,1, \ldots, 5$, parâmetros a serem estudados; $\mathrm{e}_{\mathrm{i}}$, erro aleatório atribuído a cada observação $Y_{i}$.

A partir do modelo completo acima apresentado, a escolha da equação que melhor se ajustou aos dados baseou-se no coeficiente de determinação $\mathrm{R}^{2}$, na significância da regressão e nos desvios da regressão testados pelo teste de $\mathrm{F}$ (até $5 \%$ de probabilidade) e na significância dos coeficientes de regressão testados pelo teste de $\mathrm{t}$ de Student (até 10\% de probabilidade). A equação de algumas variáveis que não foram bem explicadas pela análise de superfície de resposta foi obtida por regressão simples, como PMS, TC e ALMS. 


\section{Resultados e Discussão}

Os resultados referentes à produção de matéria seca (PMS) e produção total de MS (PTMS) não apresentaram relação significativa com os RMS e o tempo de avaliação (Tabela 1), pois a PMS e PTMS são a expressão da taxa de acúmulo de MS/ha/dia. Mesmo com o envelhecimento do pasto ao longo do tempo, observou-se que não houve declínio marcante na PMS entre os resíduos, com exceção do RMS de $3965 \mathrm{~kg} / \mathrm{ha}$. Isto pode ser explicado pelas adubações nitrogenadas fracionadas, pelo nível de fertilidade do solo e principalmente pela freqüência de chuvas, sendo 11,$5 ; 92,8 ; 37,4$ e $76,8 \mathrm{~mm}$, respectivamente, a cada período de amostragem. A PMS variou de 3717 a $8159 \mathrm{~kg}$ de MS/ha, valores inferiores àqueles obtidos por GOMES et al. (1997), trabalhando com essa cultivar em parcelas adubadas com $400 \mathrm{~kg}$ de N/ha, no mesmo período estacional.

A taxa de crescimento (TC) e a acumulação líquida de MS do pasto não foram afetadas pelos níveis de resíduo de MS e o tempo do experimento (Tabelas 2 e 3). Como o acúmulo de MS total do pasto é produto do somatório das taxas de crescimento diárias, este também não sofreu a influência dos níveis de resíduo de MS e o tempo do experimento (Tabela 3). Resultados semelhantes foram relatados por CANTO (1994) em pastagens de azevém mais trevo branco, com resíduos que variaram de 1119 a $2483 \mathrm{~kg}$ de MS/ha. Em função da maior área fotossintética ocasionada pelo aumento da área foliare dainterceptação da luz incidente, há um aumento na taxa de crescimento e simultaneamente no acúmulo de biomassa de forra- gem, até um certo ponto (HARRIS, 1978).

KORTE et al. (1987) citam que resíduos entre 900 e $3000 \mathrm{~kg}$ de MS/ha maximizam a taxa de acúmulo de MS, sendo que neste trabalho os resíduos se encontraram próximos aos níveis citados por este autor. Outro fator que pode explicar estes resultados pode estar ligado ao intervalo de tempo entre as amostragens nas áreas excluídas de pastejo pelas gaiolas. Isto porque ocorrem alterações no índice de área foliar (IAF) dentro e fora da gaiola, podendo-se inferir que as áreas protegidas do pastejo e com baixos resíduos de MS passaram rapidamente de um baixo IAF para um IAF ótimo, no qual ocorre a máxima taxa de acúmulo de MS, alcançando em seguida o IAF máximo. Nas áreas dentro das gaiolas, nos resíduos mais altos, suas condições já estariam próximas do IAF máximo, em que, segundo HARRIS (1978), 100\% da luz incidente é interceptada. Nas condições de IAF máximo, a taxa de crescimento começa a diminuir, principalmente, em função do sombreamento imposto pelas folhas no estrato superior das plantas sobre as folhas inferiores, que acabam se transformando em material senescente.

A altura das plantas (AP) da pastagem apresentou relação linear positiva $(\mathrm{P}<0,05)$ com os RMS e negativa com as datas de coletas, conforme mostra a Figura 1. Com o aumento do RMS ocorreu simultaneamente, incremento na altura do pasto, que variou de $4,7 \mathrm{~cm}$ no menor resíduo a $23,3 \mathrm{~cm}$ no maior resíduo, porém a altura do pasto diminuiu em todos os RMS com o decorrer do período experimental. PENNING et al. (1991), em pastagens de azevém perene e trevo branco, também verificaram que o aumento do resíduo de MS esteve associado com a altura do pasto.

Tabela 1- Produção de matéria seca (PMS) e produção total de matéria seca (PTMS), em kg/ha de MS, em função do nível de resíduo de MS (RMS) e datas de amostragem em pastagem de Coastcross- 1

Table 1 - Dry matter production (DMP), dry matter total production (DMTP - $\mathrm{kg}$ DM/ha) in function of dry matter residue levels (DMR) and sampling dates in Coastcross-1 grazing

\begin{tabular}{|c|c|c|c|c|c|c|}
\hline \multirow[b]{2}{*}{$\begin{array}{l}\text { RMS } \\
D M R\end{array}$} & \multirow[b]{2}{*}{06 a $26 / 01$} & \multicolumn{4}{|c|}{$\begin{array}{c}\text { Períodos } \\
\text { Sampling days }\end{array}$} & \multirow[b]{2}{*}{$\begin{array}{l}\text { PTMS } \\
D M P T \\
\mathrm{~kg} / \mathrm{ha}\end{array}$} \\
\hline & & $26 / 01$ a $16 / 02$ & $16 / 02$ a $09 / 03$ & 09 a $30 / 03$ & $\begin{array}{l}\text { PMS } \\
D M P \\
\mathrm{~kg} / \mathrm{ha}\end{array}$ & \\
\hline $1626\left(\mathrm{~T}_{2}\right)$ & 1160 & 2058 & 1856 & 1680 & 6754 & 8380 \\
\hline $1975\left(\mathrm{~T}_{1}^{2}\right)$ & 1500 & 739 & 2340 & 680 & 5259 & 7234 \\
\hline $1997\left(\mathrm{~T}_{1}\right)$ & 1080 & 840 & 1119 & 678 & 3717 & 5714 \\
\hline $2128\left(\mathrm{~T}_{3}\right)$ & 1560 & 1619 & 2040 & 2940 & 8159 & 10287 \\
\hline $2137\left(\mathrm{~T}_{2}\right)$ & 1279 & 2520 & 1428 & 0 & 5227 & 7360 \\
\hline $2844\left(\mathrm{~T}_{3}\right)$ & 1558 & 1764 & 1848 & 1428 & 6598 & 9442 \\
\hline $3811\left(\mathrm{~T}_{4}^{3}\right)$ & 0 & 2184 & 1361 & 2520 & 6065 & 9876 \\
\hline $3965\left(\mathrm{~T}_{4}^{4}\right)$ & 2377 & 1260 & 1008 & 0 & 4645 & 8610 \\
\hline
\end{tabular}


Rev. bras. zootec.

Tabela 2 - Taxa de crescimento (kg de MS/ha/dia), em função do nível de resíduo de matéria seca (RMS) e datas de amostragem em pastagem de Coastcross-1

Table 2 - Growth rate ( $\mathrm{kg} \mathrm{DM} / \mathrm{ha} /$ day) as a function of dry matter residue levels (DMR) and sampling dates in Coastcross-1 grazing

\begin{tabular}{|c|c|c|c|c|c|}
\hline \multirow[b]{2}{*}{$\begin{array}{l}\text { RMS } \\
D M R \\
\mathrm{~kg} / \mathrm{ha}\end{array}$} & \multicolumn{4}{|c|}{$\begin{array}{c}\text { Períodos } \\
\text { Sampling times }\end{array}$} & \multirow[b]{2}{*}{$\begin{array}{c}\text { Média } \\
\text { Mean } \\
\mathrm{kg} / \mathrm{ha} / \mathrm{dia}\end{array}$} \\
\hline & 06 a 26/01 & $26 / 01$ a $16 / 02$ & $16 / 02$ a $09 / 03$ & 09 a $30 / 03$ & \\
\hline $1626\left(\mathrm{~T}_{2}\right)$ & 55,2 & 98,0 & 88,4 & 80,0 & 80,4 \\
\hline $1975\left(\mathrm{~T}_{1}\right)$ & 71,4 & 35,2 & 111,4 & 32,4 & 62,6 \\
\hline $1997\left(\mathrm{~T}_{1}\right)$ & 51,4 & 40,0 & 53,3 & 32,3 & 44,3 \\
\hline $2128\left(\mathrm{~T}_{3}\right)$ & 74,3 & 77,1 & 97,1 & 140,0 & 97,1 \\
\hline $2137\left(\mathrm{~T}_{2}^{3}\right)$ & 60,9 & 120,0 & 68,0 & 0 & 62,2 \\
\hline $2844\left(\mathrm{~T}_{3}\right)$ & 74,2 & 84,0 & 88,0 & 68,0 & 78,6 \\
\hline $3811\left(\mathrm{~T}_{4}^{3}\right)$ & 0 & 104,0 & 64,8 & 120,0 & 72,2 \\
\hline $3965\left(\mathrm{~T}_{4}\right)$ & 113,2 & 60,0 & 48,0 & 0 & 55,3 \\
\hline
\end{tabular}

Muitos pesquisadores preconizam o manejo da pastagem com base em estimativas da altura das plantas.

Conforme comprovado neste experimento, o referido parâmetro serviu como bom indicador dos níveis de MS/ha. Para condições de alta ou muito baixa fertilidade do solo e, em espécies de plantas com estruturas diferentes, este manejo deve ser visto com restrições, pois podem ser encontrados pastos com alturas semelhantes, porém com resíduo de MS em kg/ha diferentes. Frame (1981), citado por CANTO (1994), comenta que a altura do pasto, quando usada para estimar o resíduo de MS/ha, tem maior precisão quando se utilizam a densidade e a composição botânica uniforme. Conforme verificado pelos valores estimados da altura do pasto, ao longo do período experimental, pequenas variações na altura corresponderam a diferenças significativas nos RMS.
A porcentagem de solo descoberto (SD) decresceu linearmente, à medida que aumentou a quantidade de forragem presente em $\mathrm{kg}$ de MS/ha e cresceu linearmente ao longo do período experimental em todos os níveis de resíduo de MS (Figura 2). Nos níveis de MS/ha de 1978, 2130 e 2545 kg este percentual teve crescimento mais acentuado ao longo do experimento, quando comparado ao nível de MS de $3857 \mathrm{~kg}$ de MS/ha.

Áreas de solo sem cobertura podem causar danos ao sistema, pois influenciam a compactação e densidade do solo, o peso das raízes das plantas e as perdas da água superficial, acelerando o processo de degradação das pastagens, além de diminuir a produção de forragem (MORAES, 1991). Portanto, pode-se afirmar que para um manejo adequado da pastagem deve-se também considerar a proporção de solo des-

Tabela 3 - Acumulação líquida de matéria seca (ALMS), por período de amostragem, em função dos resíduos de matéria seca (RMS) em pastagem de Coastcross-1

Table 3 - Liquid accumulation rate of dry matter (LADM), in function of dry matter residue levels (DMR) and sampling dates in Coastcross-1 grazing

\begin{tabular}{|c|c|c|c|c|c|}
\hline \multirow[b]{2}{*}{$\begin{array}{l}\text { RMS } \\
D M R \\
\mathrm{~kg} / \mathrm{ha}\end{array}$} & \multicolumn{4}{|c|}{$\begin{array}{c}\text { Períodos } \\
\text { Sampling times }\end{array}$} & \multirow[b]{2}{*}{$\begin{array}{c}\text { Total } \\
\mathrm{kg} \text { MS/ha }\end{array}$} \\
\hline & 06 a 26/01 & 26/01 a 16/02 & $16 / 02$ a 09/03 & 09 a 30/03 & \\
\hline $1626\left(\mathrm{~T}_{2}\right)$ & 984 & 904 & -80 & 448 & 2256 \\
\hline $1975\left(\mathrm{~T}_{1}\right)$ & 88 & 1488 & -24 & 128 & 1680 \\
\hline $1997\left(\mathrm{~T}_{1}\right)$ & 816 & 1336 & 1232 & 152 & 3536 \\
\hline $2128\left(\mathrm{~T}_{3}\right)$ & 368 & 520 & 592 & -72 & 1408 \\
\hline $2137\left(\mathrm{~T}_{2}^{3}\right)$ & 8 & 408 & 1368 & -264 & 1520 \\
\hline $2844\left(\mathrm{~T}_{3}\right)$ & -56 & 680 & 1440 & 232 & 2296 \\
\hline $3811\left(\mathrm{~T}_{4}\right)$ & -736 & -168 & 1328 & 64 & 360 \\
\hline $3965\left(\mathrm{~T}_{4}^{4}\right)$ & -2312 & 2832 & 1136 & 712 & 944 \\
\hline
\end{tabular}




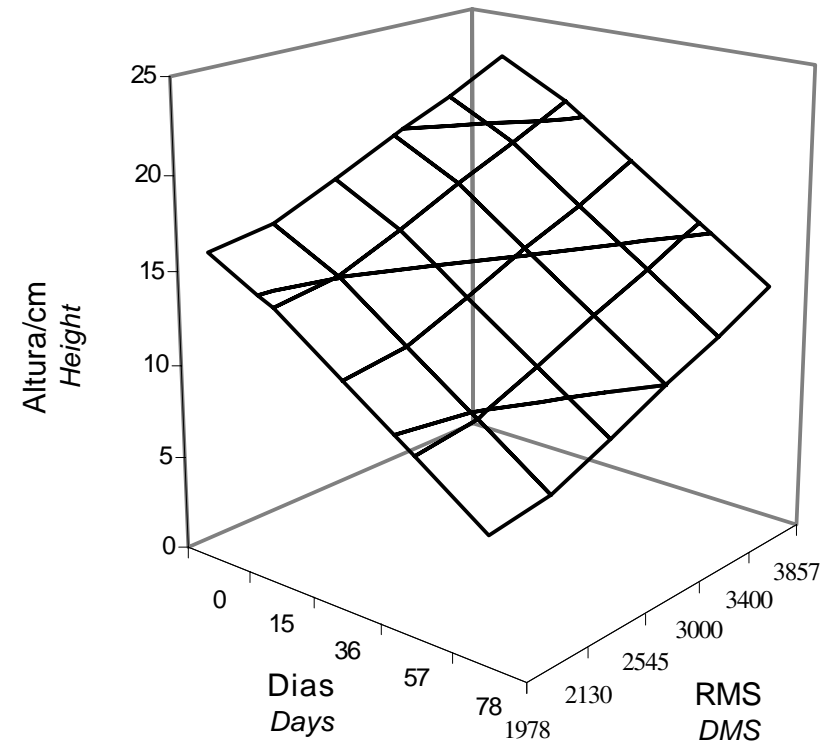

Figura 1 - Altura de plantas de Coastcross-1 em pastagem, em função dos níveis de RMS (kg MS/ha) ao longo do período experimental (dias) $P<0,05$; $\mathrm{AP}=9,93+0,00329 \mathrm{RMS}-0,1258$ dias $\left(R^{2}=0,84\right)$.

Figure 1 - Plants heigth in samples of Coastcross-1 pasture, according to dry matter residue levels (kg DM/ha) and length of experimental period.

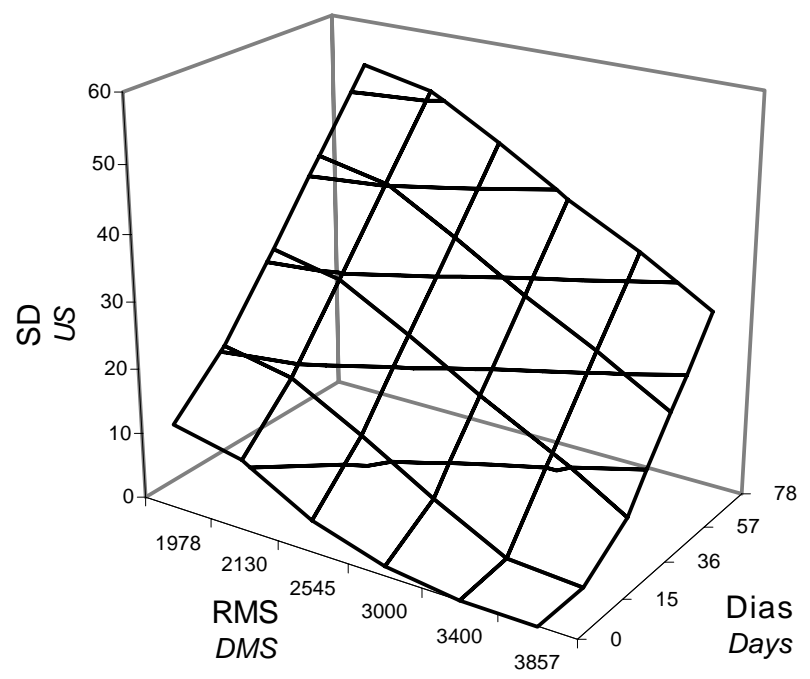

Figura 2 - Porcentagem de solo descoberto (SD\%) em pastagem de Coastcross-1, em função dos níveis RMS (kg MS/ha), ao longo do período experimental (dias). $P<0,05 ; S D=40,69-0,01406 R M S+0,518$ dias $\left(R^{2}=0,68\right)$.

Figure 2 - Uncovered soil percentage (US\%) in samples Coastcross-1 pasture, according to dry matter residue levels (kg DM/ha) and length of experimental period. coberto, evitando-se menores resíduos de MS.

A variação da percentagem de solo descoberto (SD) foi de 1 e 89,2\% para resíduo de 3857 e $1978 \mathrm{~kg}$ de MS/ha. Isto permitiu que o resíduo no nível mais alto apresentasse valores médios inferiores a $7 \%$ de solo descoberto, sendo o que mais favorece a conservação do solo. A manutenção de maior cobertura vegetal, provavelmente, possibilitou à planta maior retenção de água no solo e permitiu maior crescimento das plantas, promovendo redução na quantidade de material morto na pastagem (Figura 3).

$\mathrm{O}$ aumento da porcentagem de solo descoberto, em função do tempo (dias) do experimento, deve estar associado à redução da massa de forragem residual na pastagem e da altura de plantas (Figura 1), pois, à medida que se prolongou o período do experimento, ocorreu redução nestes parâmetros.

A porcentagem de material morto (MM) diminuiu com o aumento dos níveis residuais de MS da forragem (Figura 3), porém ao longo do período experimental a porcentagem de material morto elevou-se linearmente em todos os níveis de resíduo de MS, fato que está associado ao envelhecimento do pasto, que ocorre através da taxa de senescência em afilhos e

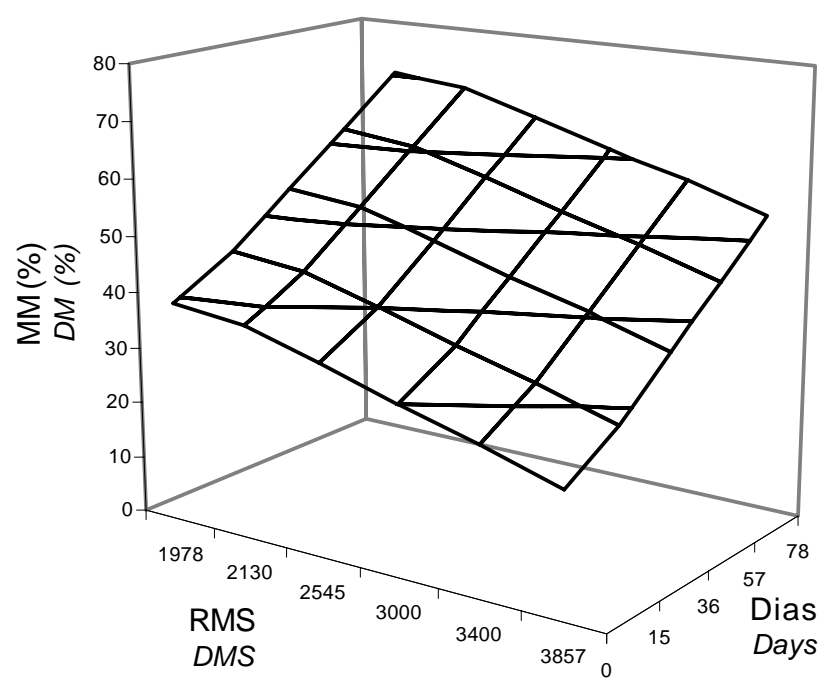

Figura 3 - Porcentagem de material morto (MM\%) de Coastcross-1 em pastagem, em função dos níveis de RMS (kg/ha de MS), ao longo do período experimental (dias). $\mathrm{P}<0,05 ; \mathrm{MM}=57,5$ $0,00918 R M S+0,3993$ dias $\left(R^{2}=0,54\right)$.

Figure 3 - Dead material percentage (DM\%) in samples of Coastcross-1 pasture, according to dry matter residue levels (kg DM/ha) and length of experimental period. 
folhas, principalmente quando estes se localizavam nos estratos inferiores da estrutura das plantas. Resultados semelhantes foram encontrados por CANTO (1994) em pastagens de azevém mais trevo branco com cordeiros em pastejo.

Segundo alguns pesquisadores, destacando-se MOOJEN (1991), existe uma relação crescente e positiva entre a proporção de RMS e o material morto. No presente trabalho, os dados contrariam esses fatos, pois, à medida que se aumentou o RMS, reduziu-se o material morto. Os fatores que determinaram esse comportamento das plantas provavelmente estejam associados ao rebaixamento imposto aos pastos com resíduos diferentes no início do experimento, fazendo com que a proporção de MM fosse diminuida nos níveis que mantinham altura superior ou maior de RMS. Os maiores resíduos mantiveram seus estratos superiores, formados em grande parte por folhas e colmos verdes, e menos material morto.

A quantidade de folhas verdes/ha $(\mathrm{FVH})$ apresentou comportamento linear positivo $(\mathrm{P}<0,05)$ nos diferentes níveis de resíduo (Figura 4), todavia, o inverso ocorreu com o passar dos dias do experimento, havendo queda na FVH em todos os níveis de RMS, chegando no nível de $1978 \mathrm{~kg}$ de MS/ha próximo de zero, na última amostragem.

Maiores quantidades de FVH com maior MS de forragem/ha já eram esperados e confirmaram os resultados obtidos por PENNING et al. (1991). A redução na FVH é explicada pela diminuição da participação do componente folhas verdes na composição do pasto (Figura 5), com o avançar do seu estádio de crescimento, principalmente nos resíduos mais baixos, chegando a quantidades abaixo de $20 \mathrm{~kg} / \mathrm{ha}$ de MS de folhas verdes, na última amostragem. Esta condição é recomendável para se obter bom desempenho na produção animal.

A necessidade de se estimar a FVH disponível nos resíduos em uma pastagem pode explicar melhor a resposta animal, considerando que a apreensão da forragem pelos animais (BURNS et al., 1989), a composição química e os aspectos nutricionais variam entre os tratamentos, podendo melhorar os resultados das pesquisas que usam animais em pastejo.

A porcentagem do componente folhas verdes (FV) na composição do pasto teve comportamento linear crescente em relação aos níveis de MS (Figura 5). Certamente, isso ocorreu devido ao rebaixamento imposto no início do experimento, afetando a participação deste componente nos níveis de MS/ha, pois nos

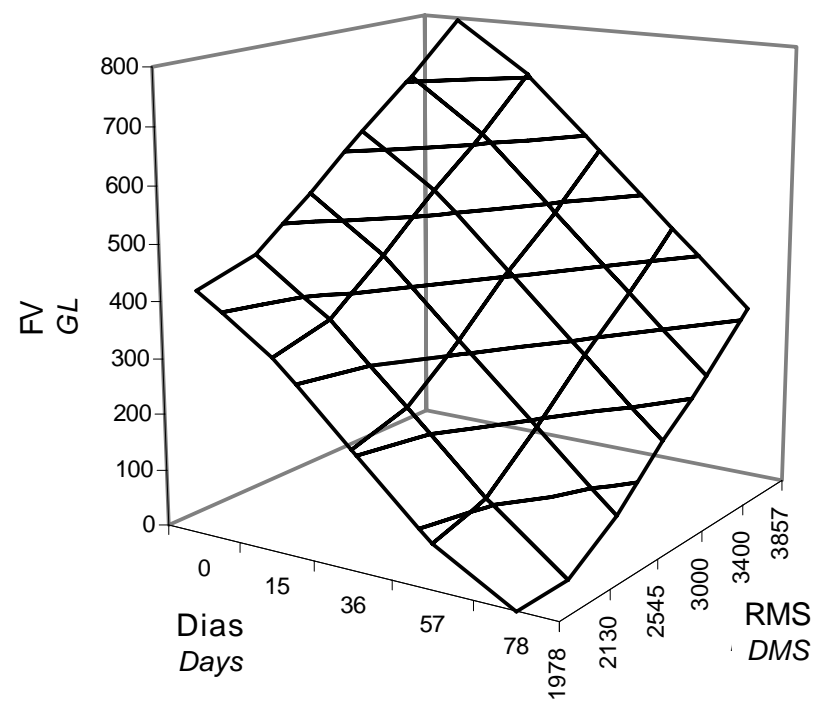

Figura 4 - Folhas verdes(FV), kg/hadeMS, de Coastcross-1em pastagem, em função dos níveis de RMS (kg/ha de MS), ao longo do período experimental (dias). $\mathrm{P}<0,05 ; \mathrm{FVH}=45,03+0,195 \mathrm{RMS}-6,168$ dias; $\left(R^{2}=0,86\right)$.

Figure 4 - Green leaves (GL), $\mathrm{kg} D \mathrm{D} / \mathrm{ha}$, in samples of Coastcross-1 pasture, according to dry matter residue levels (kg DM/ha) and length of experimental period.

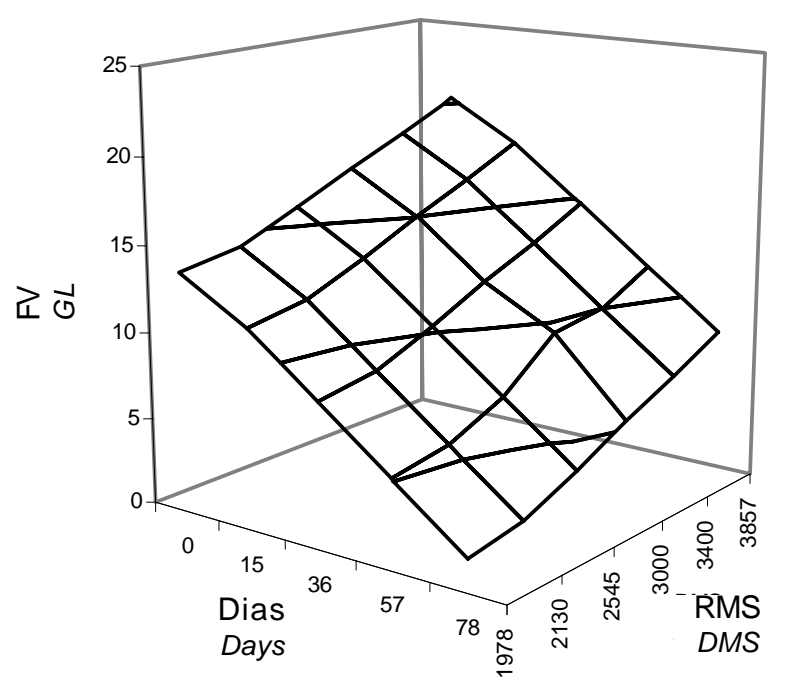

Figura 5 - Folhas verdes (FV\%) em pastagem de Coastcross-1 em pastagem, em função dos níveis de RMS (kg $\mathrm{MS} / \mathrm{ha}$ ) ao longo do período experimental (dias). $\mathrm{P}<0,05 ; \mathrm{FV}=7,074+0,00342 \mathrm{RMS}-0,15318$ dias $\left(R^{2}=0,72\right)$.

Figure 5 - Green leaves (GL\%) in samples of Coastcross-1 pasture, according to dry matter residue levels ( $\mathrm{kg} \mathrm{DM} / \mathrm{ha}$ ) and length of experimental period. 
menores resíduos o estrato basal teve participação considerável na composição estrutural do pasto, com grande porcentagem de colmo e material morto. Os maiores resíduos tiveram os estratos superiores menos danificados pelo rebaixamento, em relação ao percentual de folhas verdes.

Em relação ao tempo, o percentual de FV diminuiu na composição da pastagem em todos os resíduos de MS. Isto está associado à maturidade das plantas. Resultado semelhante foi encontrado por REIS et al. (1992). A porcentagem de colmos (C) não teve variação significativa $(\mathrm{P}<0,05)$, mas representou quantidade importante da composição da pastagem em todos os níveis de resíduo e ao longo do experimento.

A relação folha/colmo (F/C) aumentou linearmente, à medida que a quantidade de MS disponível da forragem/ha se elevou, porém o inverso ocorreu ao longo do período (dias) do experimento, a relação F/C diminuiu em todos os níveis de resíduo de MS, sendo esta queda mais acentuada nos níveis mais baixos de resíduo de MS (Figura 6). Isto é explicado pelos mesmos aspectos já mencionados na participação percentual do componente folha verde na estrutura do pasto. Estes resultados con-

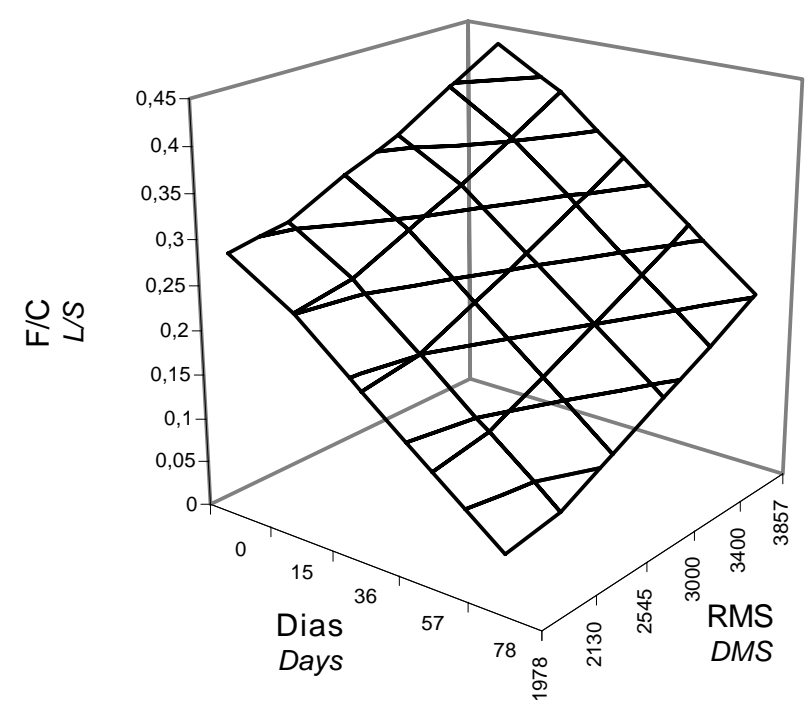

Figura 6 - Relação folha/colmo (F/C) de Coastcross-1 em pastagem, em função dos níveis de RMS (kg MS/ ha), ao longo do período experimental (dias). $\mathrm{P}<0,05 ; \mathrm{FC}=0,1513+0,0000723 \mathrm{RMS}-0,00292$ dias $\left(R^{2}=0,65\right)$.

Figure 6 - Leaf/stem ratio (L/S) in samples of Coastcross-1 pasture, according to dry matter residue levels ( $\mathrm{kg} D \mathrm{D} / \mathrm{ha}$ ) and length of experimental period. trariam os relatados por CANTO (1994), porém este autor trabalhou com pastagens de azevém e trevo branco. Por outro lado, estes resultados revelam que, com a manutenção de maior quantidade de MS residual, provavelmente, as plantas irão manter maior índice de área foliar e poderão produzir maior quantidade de matéria seca de folhas/ha (MOOJEN, 1991). Esta relação pode influenciar a qualidade do pasto quanto à sua composição química $\mathrm{e}$ digestibilidade, melhorando o desempenho animal (KORTE et al., 1987).

\section{Conclusões}

O manejo de pastagens, tendo como base a manutenção de níveis de resíduo de matéria seca presentes na pastagem, tem efeitos importantes na relação dos componentes botânicos do pasto, como folha e colmo de Coastcross-1, porém produção de MS semelhante.

A altura do pasto mostrou ser um componente importante para o manejo, por ser um parâmetro adequado para estimar os resíduos de MS, sugerindo ser a altura de $17,5 \mathrm{~cm}$ a que melhor proporcionou resíduo de MS mais adequado para o pastejo de ovinos em Coastcross-1. Nesta condição, o pasto apresentou maior fração de FV do que colmos e possibilitou menor área de solo descoberto e material morto.

O avanço do estádio de crescimento das plantas interferiu na altura das plantas, porcentagem de folhas verdes, folhas verdes/ha, relação folha/colmo, percentagem de solo descoberto e material morto, mas não interferiu na produção de matéria seca e taxa de crescimento do pasto.

\section{Referências Bibliográficas}

BURNS, J.C., LIPKE, H., FISCHER, D.S. 1989. Grayzing research: design, methodology and analysis. In: MARTEN, G.C. (Ed.) The relationship of herbage mass characteristics to animal responses in grazing experiments. Madison. cap.2, p.7-19.

CAMPBELL, A.G. 1966. Grazed pastures parameters. Pasture dry-matter producion and availability in a stocking rate and grazing management experiment with dairy cows. J. Agric. Sci., 67(2):211.

CANTO, W.M. Produção de cordeiros em pastagem de azevém (Lolium multiflorum Lam.) + trevo branco (Trifolium repens L.) submetida a níveis de resíduos de forragem. Santa Maria, RS: UFSM, 1994. 181p. Dissertacão (Mestrado em Zootecnia) - Universidade Federal Santa Maria, 1994.

CORRÊA, A.R. 1996. Forrageiras: aptidão climática do Estado do Paraná. In: MONTEIRO, A.L.G., MORAES, A., CORRÊA, E.A.S. et al. (Eds.) Forragicultura no Paraná. Londrina: CPAF. p.75-92. 
Rev. bras. zootec.

DURING, C., DYSON, C.B., WEBBY, R.W. 1980. The relationship of pasture parameters to liveweigth gain of hoggets on North Island Hill Country. Proceedings of the New Zealand Society Animal Production, Hamilton. v.40, p.98-105.

GARDNER, A.L. 1986. Técnicas de pesquisa em pastagens e aplicabilidade de resultados em sistemas de produção. In: Medição dos atributos das pastagens em experimentos de pastejo. Brasília: EMBRAPA. p.113-140.

GOMES, L.H., CECATO, U., ÍTAVO, L.C.V. et al. Avaliação de cultivares do gênero Cynodon sob níveis de adubação nitrogenada. In: REUNIÃO ANUAL DA SOCIEDADE BRASILEIRA DE ZOOTECNIA, 1997, Juiz de Fora. Anais... Viçosa: SBZ, 1997. p.33-35.

HARRIS, W. Plant relations in pastures. 1978. In: WILSON, J.R. (Ed.) Defoliation as a determinant of the growth, persistence and composition of pasture. Melbourne. cap.5, p.67-85.

HERRERA, R.S. 1983. La calidad de los pastos In: Los pastos em Cuba. La Habana: Instituto de Ciencia Animal. p.59-115.

HODGSON, J. 1979. Nomenclature in grazing studies. Grass Forage Sci., 34:11-18.

KORTE, C.J., CHU, A.C.P., FIELD, T.R.O. 1987. Feeding Livestock on pasture. In: NICOL, A.M. (Ed.) Pasture production. Hamilton. p.7-20.

MARASCHIN, G. E. Avaliação de forrageiras e rendimento de pastagens com o animal em pastejo. In: SIMPÓSIO INTERNACIONAL DE FORRAGICULTURA, REUNIÃO DA SOCIEDADE BRASILEIRA DE ZOOTECNIA, 31, 1994. Maringá. Anais...Maringá: EDUEM, 1994. p.65.

MOOJEN, E.L. Dinâmica e potencial produtivo de uma pastagem nativa do Rio Grande do Sul submetida a pressões de pastejo, épocas de diferimento e níveis de adubação. Porto Alegre, RS: UFRGS, 1991. 172p. Tese (Doutorado em Zootecnia) Faculdade de Agronomia/Universidade Federal do Rio Grande do Sul, 1991.

MORAES, A., MOOJEN, E.L., MARASCHIN, G.E. Comparação de métodos de estimativa de taxas de crescimento em uma pastagem submetida a diferentes pressões de pastejo. In: REUNIÃO ANUAL DA SOCIEDADE BRASILEIRA DE ZOOTECNIA, 27, 1990, Campinas. Anais ... Campinas: SBZ, 1990. p.332.

MORAES, A. Produtividade animal e dinâmica de uma pastagem de pangola (Digitaria decumbens sten), azevém (Lolium multiflorum Lam.) e trevo branco (Trifolium repens L.) submetida a diferentes pressões de pastejo. Porto Alegre, RS: UFRGS, 1991. 200p. Tese (Doutorado em Zootecnia). Faculdade de Agronomia/Universidade Federal do Rio Grande do Sul, 1991.
MOTT, G.O. Grazing pressure and the measurement of pasture production. In: INTERNATIONAL GRASSLANDCONGRESS, 1960, Pensylvania. Proceedings... Pensylvania, 1960.

MOTT, G.O., LUCAS, H.L. The design, conduct and interpretation of grazing trials on cultivated and improved pastures. In: INTERNATIONAL GRASSLAND CONGRESS, 1952, Pensylvania. Proceedings... Pensylvania: State College Press, 1952. p.1380-1385.

PENNING, P.D., PARSONS, A.J., ORR, R.J. et al. 1991. Intake and behaviour, responses by sheep to changes in sward characteristics under continuous stocking. Grass and Forage Sci., 46:15-28.

REIS, R.A., RODRIGUES, L.R.A., COAN, O. et al. 1992. Efeito de diferentes épocas de colheita sobre a produção de forragem e de sementes de aveia preta. Pesq. Agropec. Bras., 27(1):111-117.

SÁ, J.P.G. 1996. Grama Estrela, Bermuda, Coastcross-1 e Tifton Cynodon ssp. In: MONTEIRO, A.L.G. et al. (Eds.) Forragicultura no Paraná, Londrina, PR: IAPAR. p.210.

SECRETARIA DO ESTADO DO PARANÁ. 1985. Mapeamento dos municípios do Estado do Paraná. Curitiba - PR. 314p.

VILELA, D., ALVIM, M.J. Produção de leite em pastagem de Cynodon dactylon (L.) Pers, cv. "coast-cross". In: WORKSHOP SOBRE O POTENCIAL FORRAGEIRO DO GÊNERO CYNODON, 1996, Juiz de Fora. Anais... Juiz de Fora: EMBRAPA, 1996. p.77-91.

WEBBY, R.W., PENGELLY, W.J. 1986. The use of pasture heigth as a predictor of feed level in North Island Hill Country. Proceedings of the New Zealand Grassland Association, Palmerston North, 47:249-253.

WHITLOCK, J.K. 1941. A pratical dilution egg count procedure. J. Am. Vet. Med. Assoc., 47(771):466-469.

WILM, H.G., COSTEllO, O.F., KLIPPLE, G.E. 1944. Estimating forage yield by the double sampling method. J. Amer. Soc. Agron., 36(1):194-203.

Recebido em: 14/03/00 Aceito em: 25/01/01 